\title{
Detection of Pillow Block Bearings Defect Using Infrared Thermography: A Case Study in Golgohar Mining and Industrial Co.
}

\author{
byA.Ahmadipour*, A.ForoughiNematollahi* ${ }^{* *}$ and R.SotoudehBahreini ${ }^{* * *}$ \\ *Golgohar Mining and Industrial Co, Iran,Abolfazl.Ahmadipoor@Gmail.com \\ **Golgohar Mining and Industrial Co, Iran, Aforoughi.22@gmail.com \\ ${ }^{* * *}$ Golgohar Mining and Industrial Co, Iran, Rahim.sotoodeh@gmail.com
}

\begin{abstract}
The objective of this paper is to evaluate the effectiveness of infrared thermography as a non-contact, fast and reliable non-destructive evaluation procedure for detection of pillow block bearings of dry Semi-AutoGenous (SAG) mills. There are many factors affect bearing temperature such as ambient temperature, capacity rate of input materials, runtime and so on. Therefore analysis of thermography images of bearing might be affected by these many variables and lead to inaccurate results. This article describes a temperature-oriented method for determining bearing health.The results show that using proposed methods would reliably indicate bearing problemsbefore bearing fails.
\end{abstract}

\section{Introduction}

Thermography can be considered as a basic strategy in the field of maintenance engineering. Base of thermal imaging is thermal energy emitted from hot surfaces and recording an image of infrared radiation. Thermography analysis is an important technique with very wide range of applications and one of most important usages of it is condition monitoring of equipment and machinery of industry [1]. Electrical network faults are mainly due to loose and defective connections. Rotating equipment defects are mainly because of the friction caused by improper lubrication, misalignment and off-centered installation, old and worn-out parts, abnormal mechanical loads and so on [2]. Any of the mentioned mechanical and electrical defects happen can increase system temperature. If this temperature increase is recognized early, it can prevent critical defects and damage of other parts of system.

Bearings are one the most important part of equipment which their role is to provide a less-friction support and carrying the loads. Any damages in the bearing may lead to stop equipment even down time of process line. Therefore monitoring of condition of equipment is very vital. Wear and therefore friction, cause increase in bearing temperature and condition monitoring of bearing temperature can be lead to predict potential damages [2]. There are many factors affect bearing temperature such as ambient temperature, speed, capacity rate of input materials, runtime and so on. Therefore analysis of thermography images of bearing might be affected by these many variables and lead to inaccurate results. In recent years, many studies on thermography analysis have been done to detect bearing faults. In [3] how to identify roller bearing defect by thermography technique is studied. In this paper firstly, dry mills of Magnetite factory of Golgohar mining and industrial Co. are introduced, including the forces acting on its bearing and the lubrication system. Then two temperature-oriented methods for determining bearing healthis introduced. In the first method, identical or near-identical bearings mounted the same shaft are compared. This method cancels the effects of mentioned variables because they are the same for both bearings. The remaining temperature differences between two bearings on a common shaft with the same capacity rate of input materials can only be the result of friction, as an indicator of bearing problems.

In the second method, a reference working temperature is calculated by considering the factors -capacity rate of input materials, ambient temperature and runtime duration- that can contribute to temperature variation. This reference temperature could be obtained from different ways such as manufactures recommendation for safe operation temperature and recorded values of temperature. If the mentioned variable factors could be accounted for accurately, then increases in reference temperature would reliably indicate bearing problems. Finally, after a correct diagnosis and fault detection, repair is done and results of thermography analysis of equipment will be discussed.

\section{SAG mill}

Golgohar mineral and industrial company has three processing line of iron ore concentrate and there is a semiauto genius mill (dry mill) with power $3 \mathrm{Mw}$ in each one. These mills are categorized as vital equipment and any problem of them could lead to processing line down time. Figure 1 shows Schematic view of dry mill. 


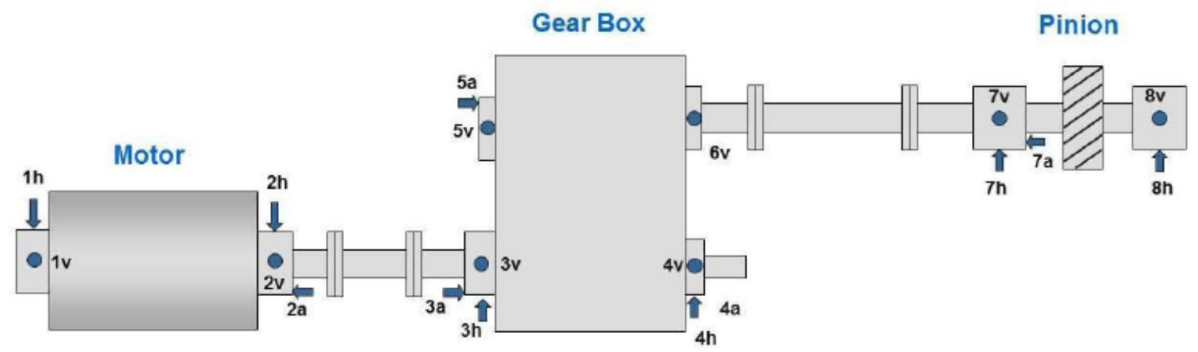

Fig. 1. Schematic of drive system of dry mill

Forces imposed to Bearings are due to the weight of the shaft and pinion reaction loads acting on pinion are from Girth gear. By calculating load on the pinion then the bearing load, it would be possible to compare bearing temperature on two sides of the pinion. Radial force acting on the bearing 7 is greater than the force on bearing number 8; also bearing 7 bears axial load imposed from pinion gear. Considering the amount of load -especially the axial loadon bearing 7 , this point is a critical one of the pinion shaft set. This case study concentrates on temperature increase of fix bearing of shaft pinion of dry mill located in Golgohar industrial and mining Co. Bearing type is self-aligning roller bearing and its No. is $23264 \mathrm{CAK}+\mathrm{AOH} 3264$. Figure 2 shows bearing drawing. The roller bearing with conical inner bore is mounted on pinion shaft using withdrawal sleeve and tightened on its place by a nut. Table 1 shows the characteristics of dry mill and includes axial and radial loads on the pinion teeth in points 7 and 8 .

From table 1 it can be seen that the radial force imposed to bearing 7 , In addition to the weight of the pinion shaft and gear load, includes coupling weight as well. This causes the radial loads on the bearing 7 are about 8000 Newton more than radial loads on the bearing 8.

Table 1. Dry mill technical data and loads

\begin{tabular}{|c|c|c|c|}
\hline $\begin{array}{c}\text { Maximum power of } \\
\text { electromotor }\end{array}$ & $3000 \mathrm{Kw}$ & Load on gear thooth & $467736 \mathrm{~N}$ \\
\hline Pinion shaft speed & $196 \mathrm{rpm}$ & $\begin{array}{c}\text { Radial load on bearing 8 (shaft } \\
\text { weight/2 + gear load/2) }\end{array}$ & $248688 \mathrm{~N}$ \\
\hline Pitch diameter of pinion & $0.345 \mathrm{~m}$ & $\begin{array}{c}\text { Radial load on bearing 7 (shaft } \\
\text { weight/2 + gear load/2 + coupling } \\
\text { weight) }\end{array}$ & $256688 \mathrm{~N}$ \\
\hline Shaft pinion weight & $29640 \mathrm{~N}$ & Axial load on bearing 7 & $90108 \mathrm{~N}$ \\
\hline
\end{tabular}

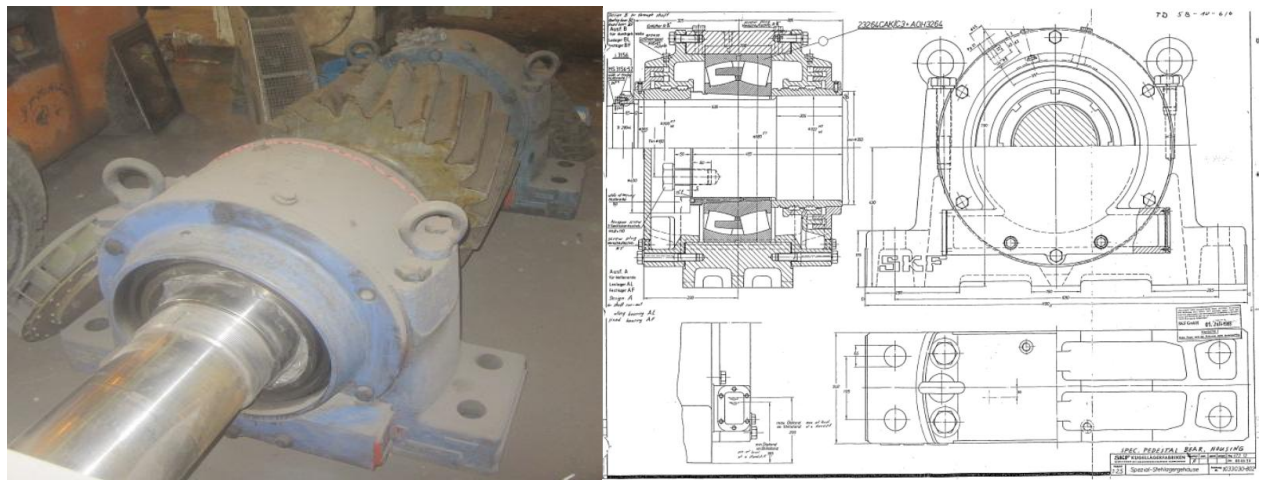

Fig. 2. Pinion shaft and bearing set

Selection of lubricant for bearing is affected by different factors such as speed, load and operating temperature range. Lubrication of mill bearing is done by central lubrication. The most important components of lubrication system are oil tank, level gauge, gear pump, filter, relief valve and pressure gauge. Theoil level gauge shows the oil level and it is equipped by a thermometer which measures the oil temperature. The central lubrication system of mill is shown in figure 3. 


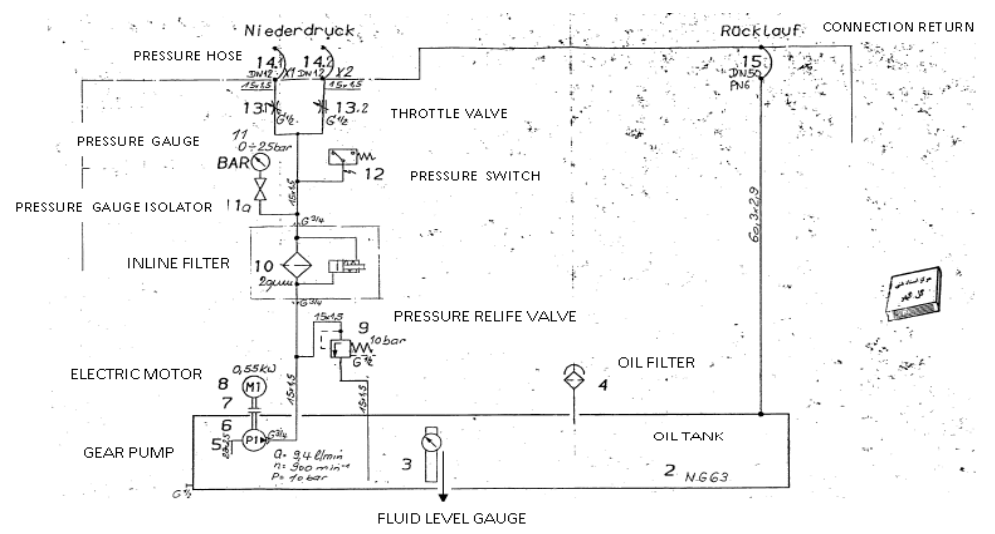

Fig. 3.Central lubrication system of SAG-mill

\section{Bearing temperature}

The permissible range for sealed bearings (ES-2RS design) is limited by the operating temperature range of the seal material (polyester elastomer -30 to $+130^{\circ} \mathrm{C}$; polyurethane -20 to $+80^{\circ} \mathrm{C}$ ). The operating temperature range for the actual grease used to lubricate the bearings must also be taken into account. The permissible operating temperature for track runner bearings is mainly limited by the dimensional stability of the cage, seals,lubricantbearing rings and rolling elements [4].

The temperature range of cage which is made by stainless steel is equal to the temperature range ofrotary components and bearing rings. The temperature range for other material cages can be obtained by using manufacture recommendation

\section{Thermography of SAG-millBearing}

The infrared thermography inspection of SAG-mill bearings was conductedseveral times and the results are written in. The date of each data acquisition is indicated at table 2.This infrared thermography inspection was conducted by using HOTFIND LX camera. Figure 4 shows thermography image of bearing7.

Table 2.Dates of data acquisition

\begin{tabular}{|c|c|}
\hline Number & Date \\
\hline 1 & Monday, April 21, 2014Bottom of Form \\
\hline 2 & Wednesday, April 23, 2014Bottom of Form \\
\hline 3 & Saturday, April 26, 2014Bottom of Form \\
\hline 4 & Sunday, May 11, 2014Bottom of Form \\
\hline 5 & Sunday, July 06, 2014Bottom of Form \\
\hline 6 & Sunday, July 13, 2014Bottom of Form \\
\hline 7 & Monday, August 11, 2014Bottom of Form \\
\hline 8 & Tuesday, August 12, 2014Bottom of Form \\
\hline 9 & Monday, August 25, 2014Bottom of Form \\
\hline 10 & Sunday, August 31, 2014Bottom of Form \\
\hline
\end{tabular}




\begin{tabular}{|c|c|}
\hline Value & IR Info \\
\hline 3 & IR Num \\
\hline 0.9 & EMS \\
\hline 2 & Dist \\
\hline 30 & Env.tmp \\
\hline 54.53 & Max Temp \\
\hline & \\
&
\end{tabular}

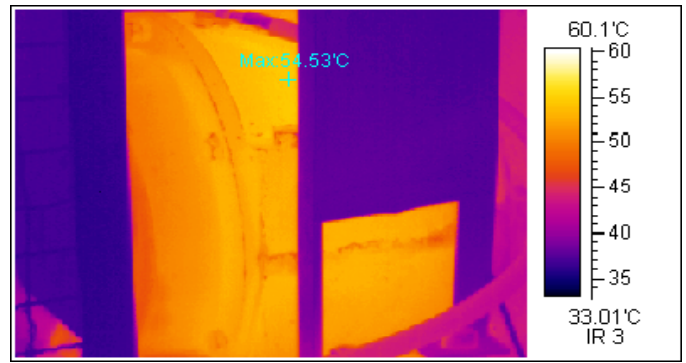

Fig. 4. Thermography image of bearing 7

Figure 5 shows bearing temperatureat each thermographyinspection. The range of temperature variationofpillow block bearing 7 is from 44 to $45^{\circ} \mathrm{C}$ in the first four data acquisition. The temperature of pillow block bearing is affected by different factors such as the ambient temperature, emissivity, relative humidity, and distance from target and also process parameters such as capacity rate of input materials and runtime duration. For the sake of simplicity, the emissivity, distance from target, relative humidity and runtime duration assumed constant for all data acquisition.The weight of SAG-mill varies with the capacity rate of input and output materials. The power of electro-motor will change directly with changes of SAG-mill weight. Consequently, the power of electro-motor is depended on the capacity rate of input and output materials of SAG-mill. The power of electro-motor is shown in figure 6.

Figure7 shows the ambient temperature at each infrared thermography inspection. The variation of ambient temperature in the first four inspections was $5^{\circ} \mathrm{C}$. The weight of SAG-mill varies with the capacity rate of input and output materials. The power of electro-motor will change directly with changes of SAG-mill weight. Consequently, the power of electro-motor is depended on the capacity rate of input and output materials of SAG-mill.

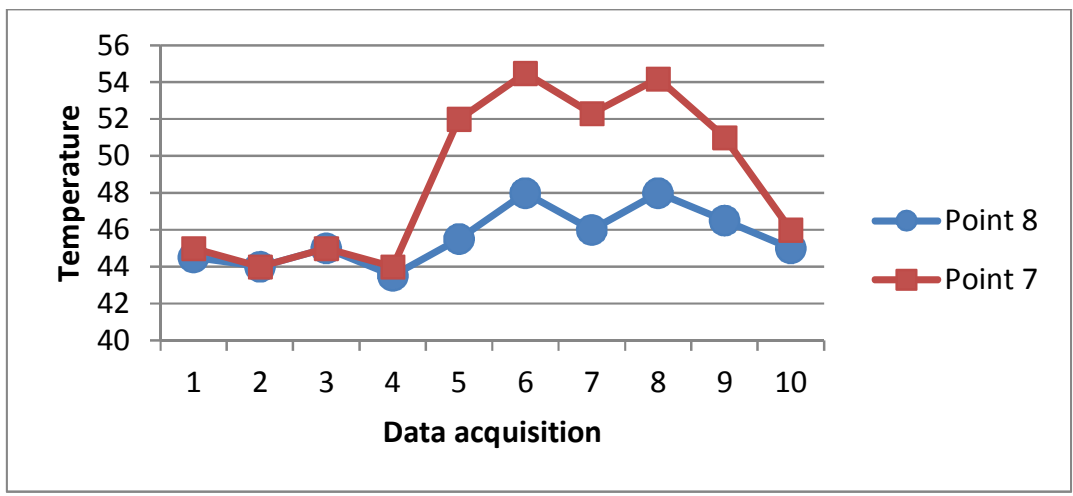

Fig. 5. Bearing temperature variations

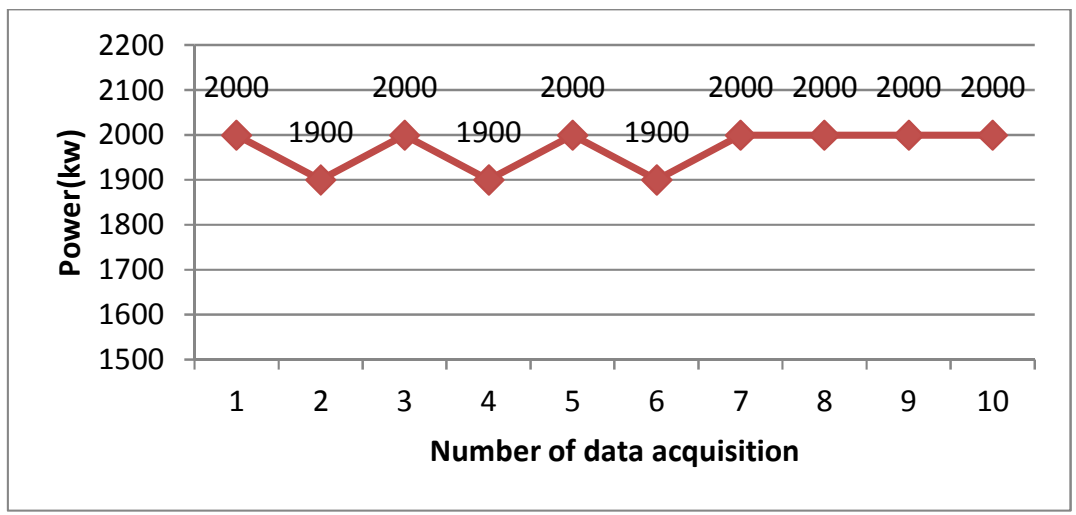

Fig. 6.Power of Electro motor 


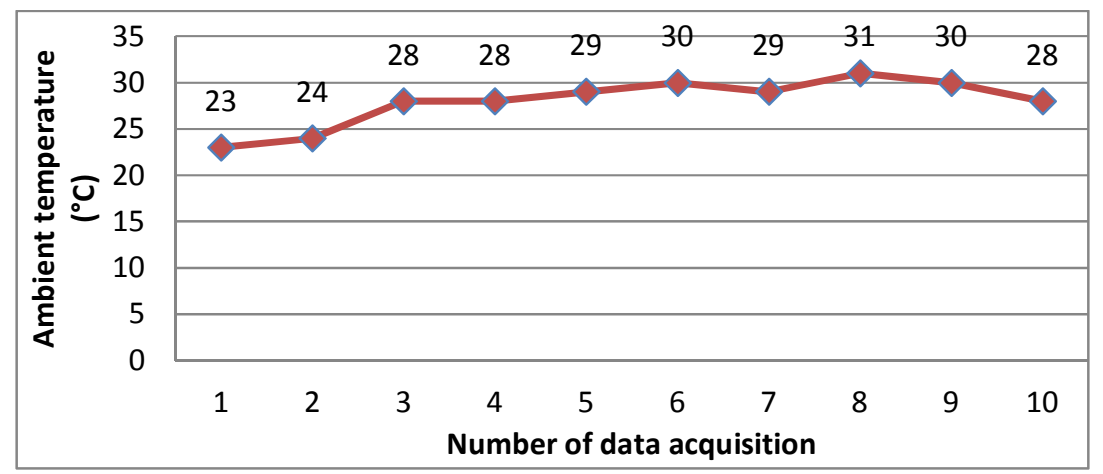

Fig. 7.Ambient temperature

\section{Fault detection of bearing}

In this section, two temperature-oriented methods are described for determining bearing health.

\subsection{Compare method}

In this method, identical or near-identical bearings mounted the same shaft are compared. This method cancels the effects of variables-capacity rate of input materials, ambient temperature and runtime duration- because they are the same for both bearings. The remaining temperature differences between two bearings on a common shaft with the same capacity rate of input materials can only be the result of friction, as an indicator of bearing problems. Some standard recommendations such as NETA can be used for compare method.

\subsubsection{NETA Standard}

The infrared thermographer may use the following Delta $\mathrm{T}$ (temperature difference) criteria to evaluate the temperature severity of an exception. These Delta $T$ criteria are reported as the temperature rise of the exception above the temperature of a defined reference, which is typically the ambient air temperature, a similar component under the same conditions or the maximum allowable temperature of the component.

Table 3.Experience-based for electrical and/or mechanical equipment

\begin{tabular}{|c|c|c|}
\hline Priority & Delta $\mathrm{T}$ & Recommended Action \\
\hline 4 & 1 to $10^{\circ} \mathrm{C}$ & Corrective measures should be taken at the next maintenance period \\
\hline 3 & $>10$ to $20^{\circ} \mathrm{C}$ & Corrective measures required as scheduling permits \\
\hline 2 & $>20$ to $40^{\circ} \mathrm{C}$ & Corrective measures required ASAP \\
\hline 1 & $>40^{\circ} \mathrm{C}$ & Corrective measures required immediately \\
\hline
\end{tabular}

\subsection{Reference temperature criteria method}

In this method, a reference working temperature is calculated by considering the factors -capacity rate of input materials, ambient temperature and runtime duration- that can contribute to temperature variation. This reference temperature could be obtained from different ways such as manufactures recommendation for safe operation temperature and recorded values of temperature. If the mentioned variable factors could be accounted for accurately, then increases in reference temperature would reliably indicate bearing problems.

\subsubsection{Manufactures recommendation for safe operation}

The device will operate effectively within a specified temperature range which varies based on the device function and application context, and ranges from the minimum operating temperature to the maximum operating temperature. Outside this range of safe operating temperature the device may fail. The SAG mill manufactures recommended the oil temperature in the oil supply system is under the maximum of $60^{\circ} \mathrm{C}$ and also the bearing temperature is under the maximum of $80^{\circ} \mathrm{C}[5]$. 


\subsubsection{Proposed method}

In this method, a reference working temperature is calculated by considering the factors -capacity rate of input materials, ambient environment temperature and runtime duration- that can contribute to temperature variation. The reference temperature criteria is based on equipment operating at a low variation of variable factors. The reference temperature is calculated from Eq. (1).

$$
T_{r}=T_{m}+S T D V
$$

In Eq. (1), $T_{r}$ is the reference temperature criteria, $T_{m}$ is mean value of temperature and STDV is standard deviation of temperature. The reference temperature is calculated from the first four data acquisition by adding the mean values to standard deviation. In this period of time, power of electrical motor is almost constant and that is near of its nominal value. Also the ambient temperature is approximately constant and it varies from $21^{\circ} \mathrm{C}$ to $26^{\circ} \mathrm{C}$. The mean value and standard deviation of first four data acquisition are 44.6 and 0.75 respectively. Consequently, the reference temperature criteria based on equipment operating is $45.3^{\circ} \mathrm{C}$ at bearing point 7 .

\section{Results and discussions}

As mentioned in section 2, the main gearbox output shaft of each SAG mill is flexibly coupled to a pinion stand and each pinion stand has two pillow block bearings. Consequently, the remaining temperature differences between these two bearings on a common shaft can only be the result of friction, as an indicator of bearing problems. As shown in figure 5, the remaining temperature between bearing 7 and bearing 8 increased in the $5^{\text {th }}$ data acquisition. The maximum remaining temperature between these two bearings is $6.5^{\circ} \mathrm{C}$. according to the NETA recommendation, the compare method doesn't show any defect in the equipment.

The bearing defect can also be obtained from reference temperature criteria method. In this case study,the manufacture recommends that the bearing temperature is under the maximum of $80^{\circ} \mathrm{C}$. therefore, diagnosis of the defect could not be obtained by manufacture recommendation. But with using the proposed method, the reference temperature criteria based on equipment operating is $45.3^{\circ} \mathrm{C}$ at bearing point 7 . The temperature of bearing 7 is $52^{\circ} \mathrm{C}$ in the $5^{\text {th }}$ data acquisition and it shows the bearing defect.

According to the manufacture recommendation, in case of high temperature of pinion bearing, lubrication of pinion bearing, running surfaces and trunnions should be checked. These items were checked when the SAG mill was overhauled. The results show that thechuck nut of bearing at point 7 was cracked. Fig. 9 shows the crack of bearing.The repair of chuck nut was done between the $8^{\text {th }}$ and $9^{\text {th }}$ data acquisition. As shown in Fig.3, the bearing temperature at point 7 decreased after the 9th data acquisition.

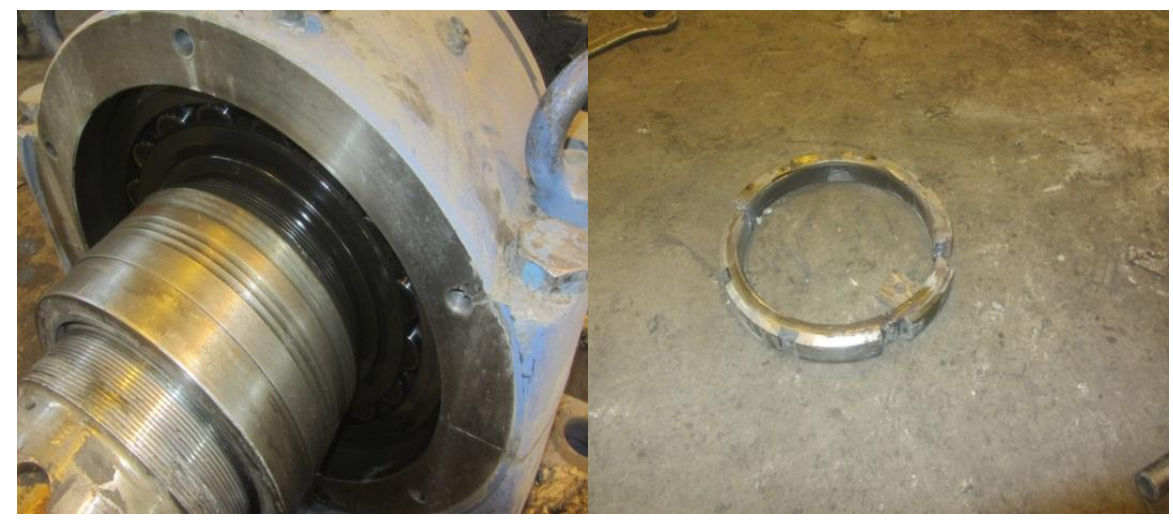

Fig. 8. Crack of chuck nut at bearing point 7

\section{Conclusion}

Thermographic techniques have been used in a variety of applications, e.g. detect of cracks and inspection of subsurface defects. This research, presented two temperature-oriented methods for determining bearing health. In the first method, identical or near-identical bearings mounted the same shaft are compared. This method cancels the effects of mentioned variables because they are the same for both bearings. In the second method, a reference working temperature is calculated by considering the factors that can contribute to temperature variation.In this case study by 
using proposed methods the bearing defect was predicted. This prediction verified when the SAG mill was overhauled. The results show that using proposed methods for analyzing infrared thermography images would reliably indicate bearing problems before bearing fails.

\section{REFERENCES}

[1] Meola C., "Infrared Thermography: Recent Advances and Future Trends". Bentham Science: New York, NY, USA, 2012.

[2] InterNational Electrical Testing Association - NETA 3050 Old Centre Avenue, Suite 102 Portage, MI 49024:www.netaworld.org

[3] Mazioud A, Ibos L, Khlaifi A, Durastanti J.F., "Detection of rolling bearing degradation using infrared thermography".9th International Conference on Quantitative Infrared Thermography, July 2-5, 2008, Krakow Poland

[4] http://www.skf.com

[5] Krupp polysius, Operation manual and spare part catalogue,TD5B

[6] Tailor J., "Vibration Analysis Handbook for Condition Monitoring \& Fault Diagnosis Engineers". First Edition,1965. 